\title{
Effects of Phosphonate Herbicides on the
}

\section{Secretions of Plant-Beneficial Compounds by Two Plant Growth-}

\section{Promoting Soil Bacteria: A Metabolomics Investigation}

\author{
Wenting $\mathrm{Li}^{1}$, Rebecca A. Wilkes ${ }^{2,3}$, Ludmilla Aristilde ${ }^{1,2,3, *}$ \\ 1 Department of Chemical and Biological Engineering, McCormick School of \\ Engineering and Applied Science, Northwestern University, Evanston, IL 60208 \\ USA \\ ${ }^{2}$ Department of Biological and Environmental Engineering, College of Agriculture \\ and Life Sciences, Cornell University, Ithaca, NY 14853 USA \\ ${ }^{3}$ Department of Civil and Environmental Engineering, McCormick School of \\ Engineering and Applied Science, Northwestern University, Evanston, IL 60208 \\ USA \\ ( ${ }^{*}$ correspondence: ludmilla.aristilde@northwestern.edu)
}




\section{Appendix A.}

\section{Relative glyphosate concentration along time.}

A
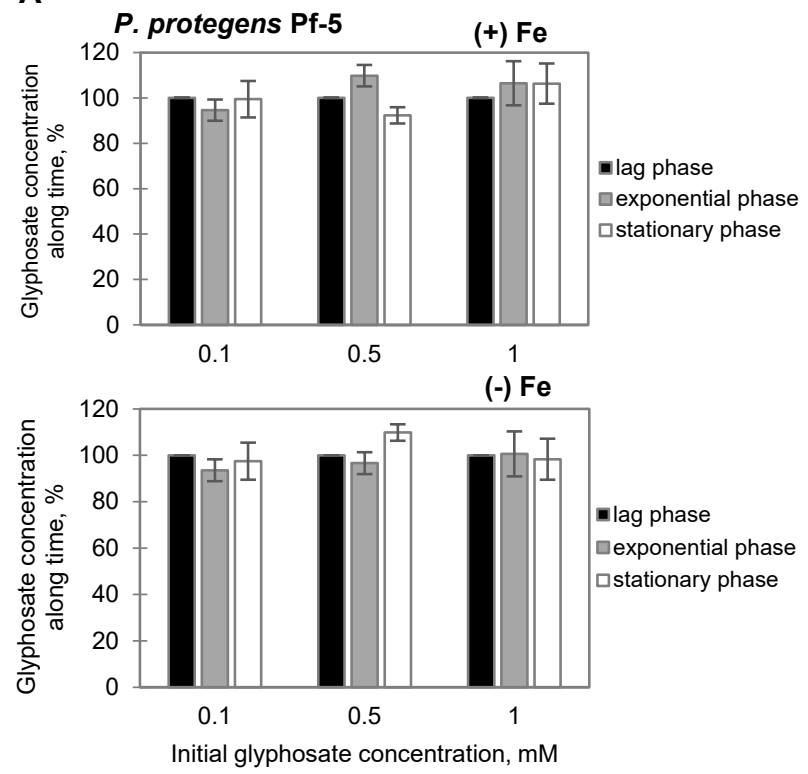

B
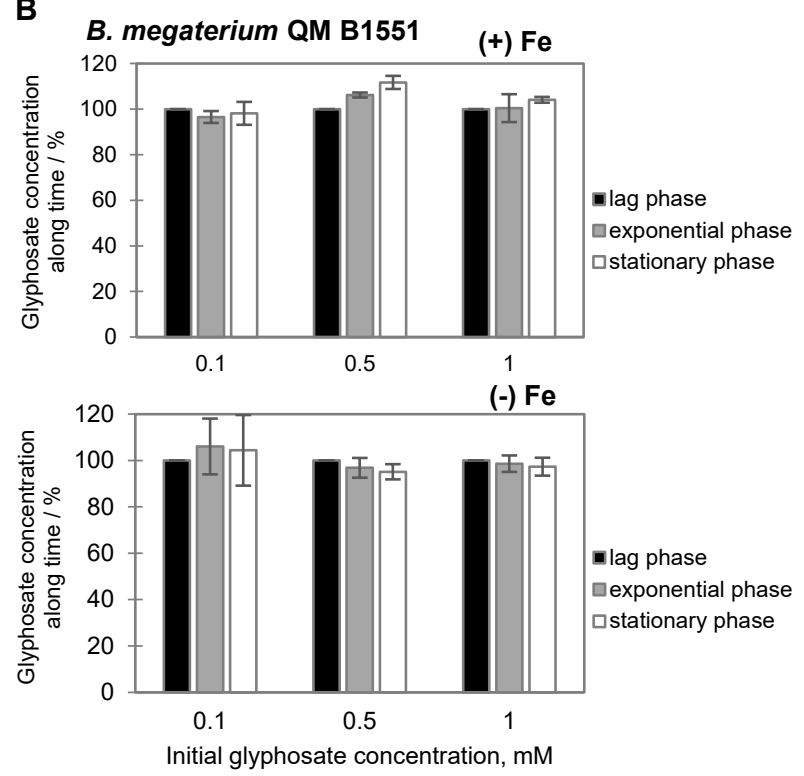

Figure S1. Relative glyphosate concentration along time of (A) P. protegens Pf-5 and (B) B. megaterium QM B1551 cells grown under (top) Fe-replete and (bottom) Felimited conditions. The data obtained from cells at lag, exponential, and stationary growth phases are shown in black, gray, and white bars, respectively. 


\section{Appendix B.}

Relative glufosinate concentration along time.

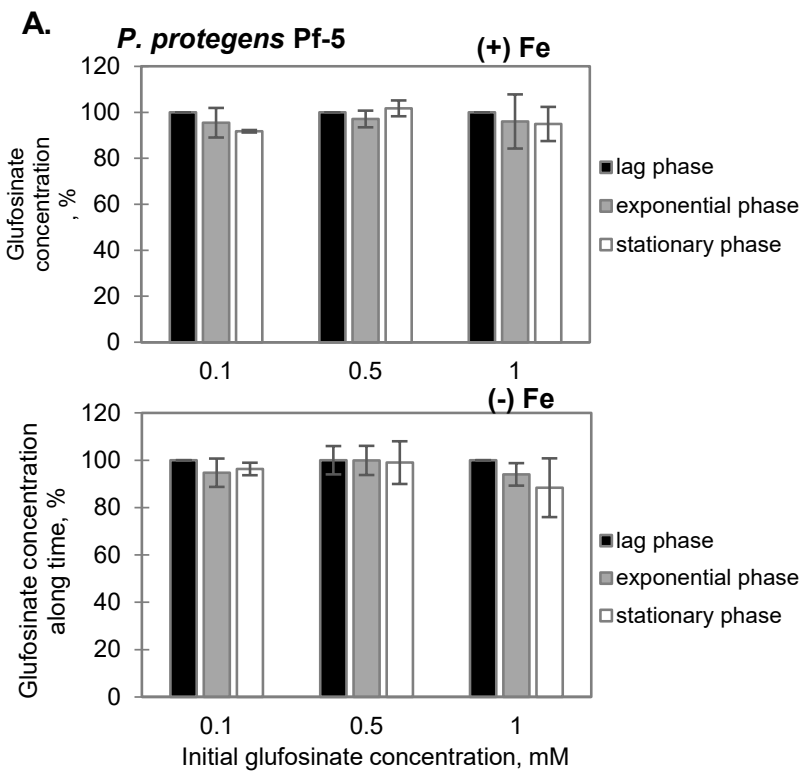

B
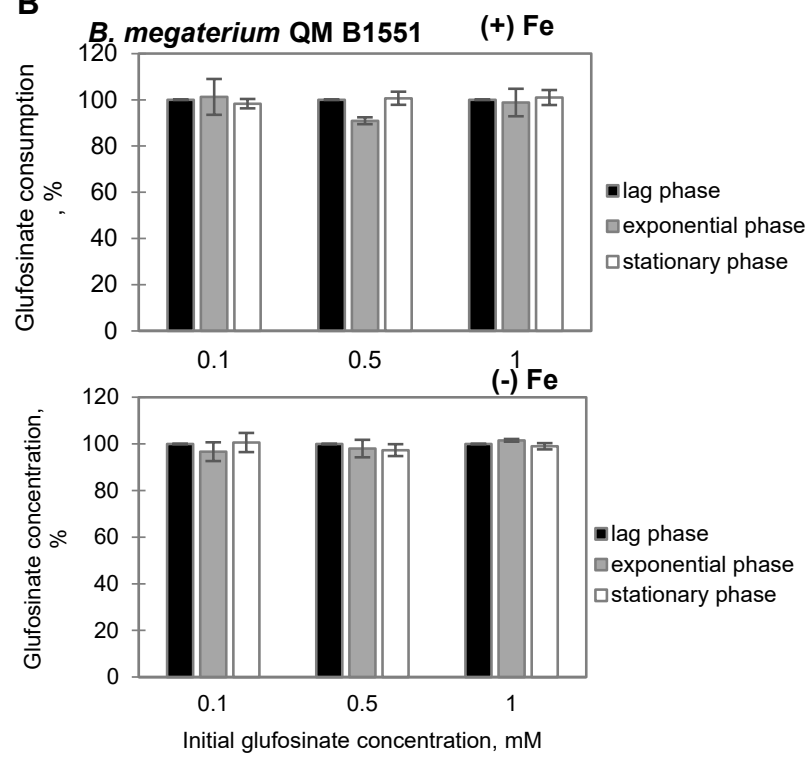

Figure S2. Relative glufosinate concentration along time of (A) P. protegens Pf-5 and (B) B. megaterium QM B1551 cells grown under (top) Fe-replete and (bottom) Fe-limited conditions. The data obtained from cells at lag, exponential, and stationary growth phases are shown in black, gray, and white bars, respectively. 


\section{Appendix C.}

Relative fosamine concentration along time.
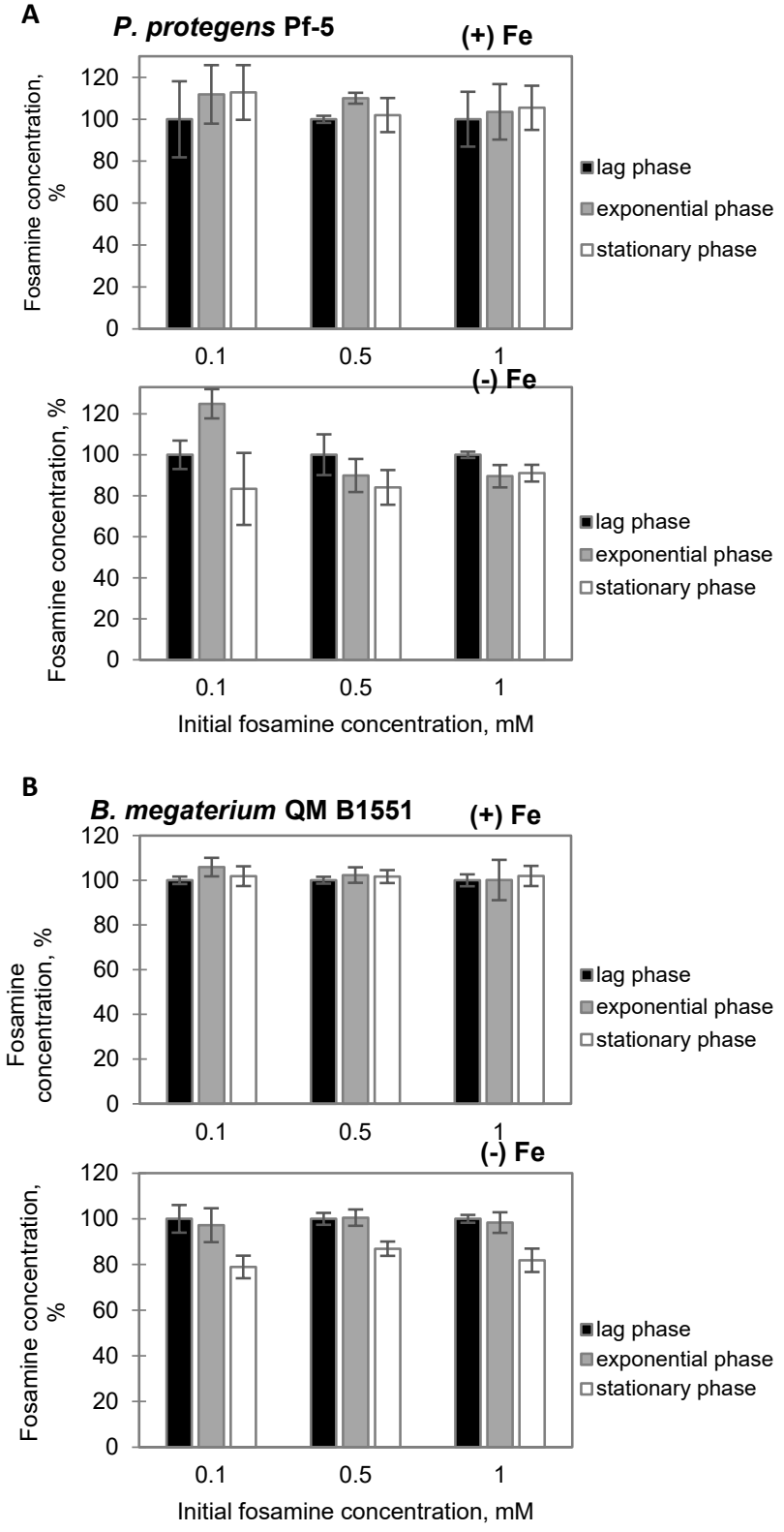

Figure S3. Relative fosamine concentration along time of (A) P. protegens Pf-5 and (B) B. megaterium QM B1551 cells grown under (top) Fe-replete and (bottom) Fe-limited conditions. The data obtained from cells at lag, exponential, and stationary growth phases are shown in black, gray, and white bars, respectively. 


\section{Appendix D. relative to control.}

\section{Metabolite levels in herbicide-exposed cells}
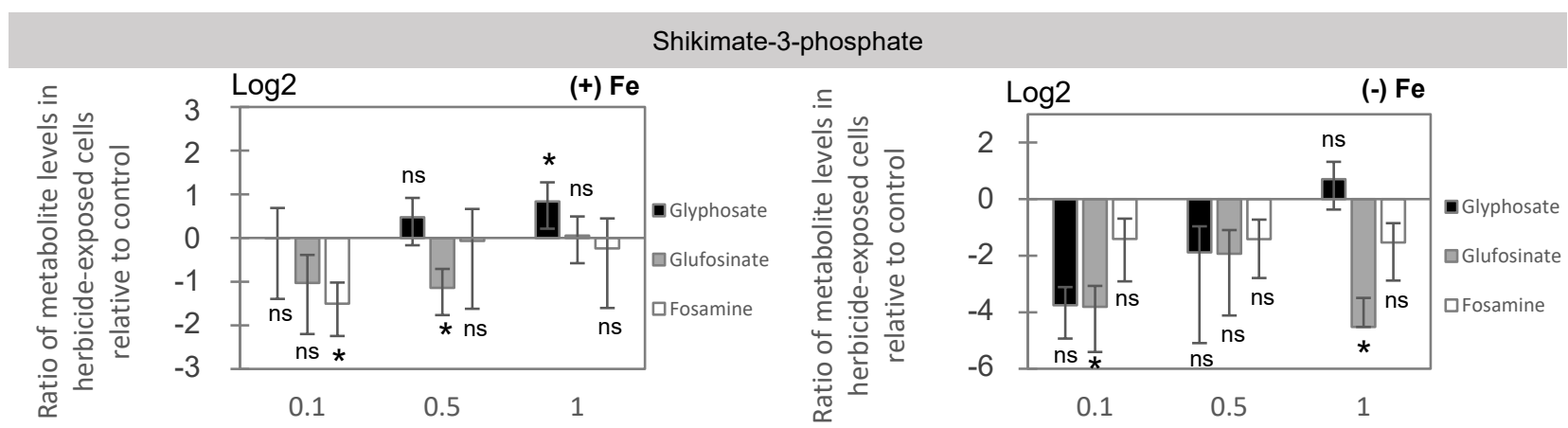

Phenylalanine

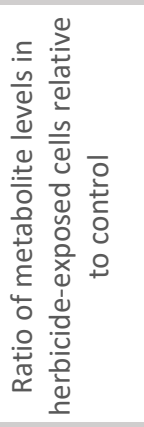

(+) Fe

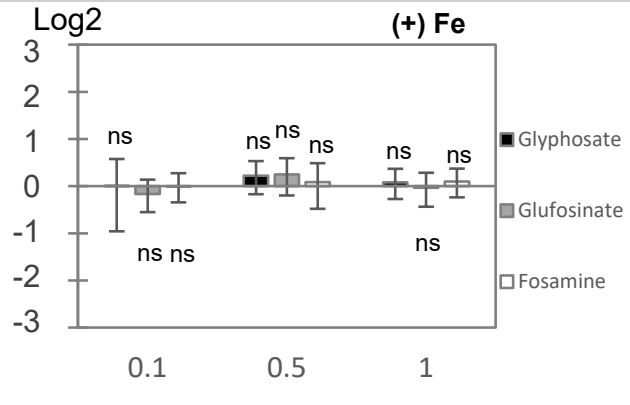

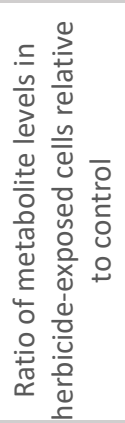

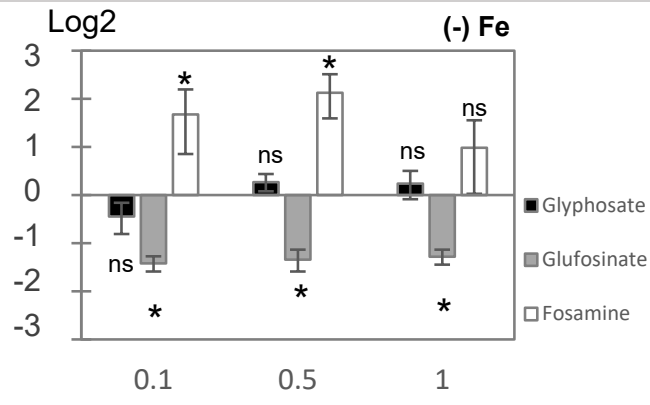

Tyrosine
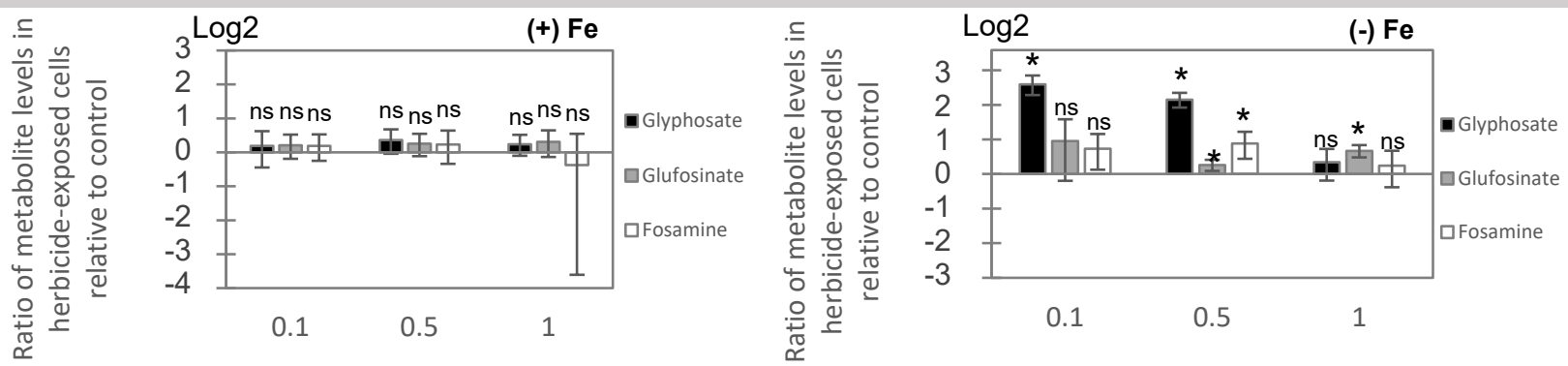

$\log 2$

(-) $\mathrm{Fe}$

Phenylacetic acid
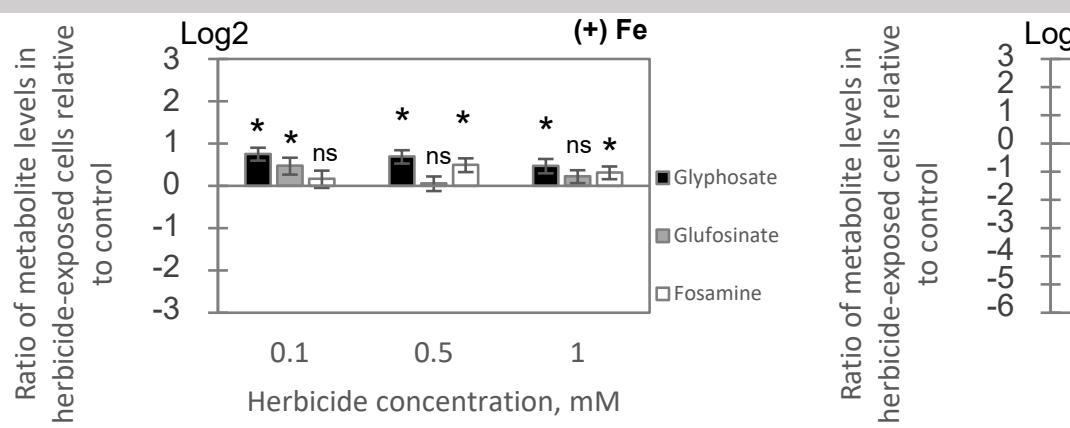

(-) Fe

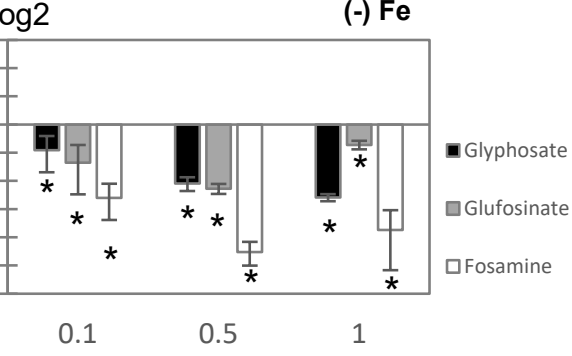

Herbicide concentration, $\mathrm{mM}$

Figure S4. The levels of metabolites involved in the auxin biosynthesis in herbicide-exposed $P$. protegens Pf- 5 cells relative to control under Fe-replete (left) and Fe-limited (right) conditions. Two-tailed unpaired t-test analysis comparing the ratios obtained with cells grown when each phosphonate herbicide was added to the nutrient medium to cells grown only on the nutrient medium : $p<0.05\left({ }^{*}\right)$, not statistically significant (ns). 
Appendix E Metabolite levels in herbicide-exposed cells Appendix E. relative to control.
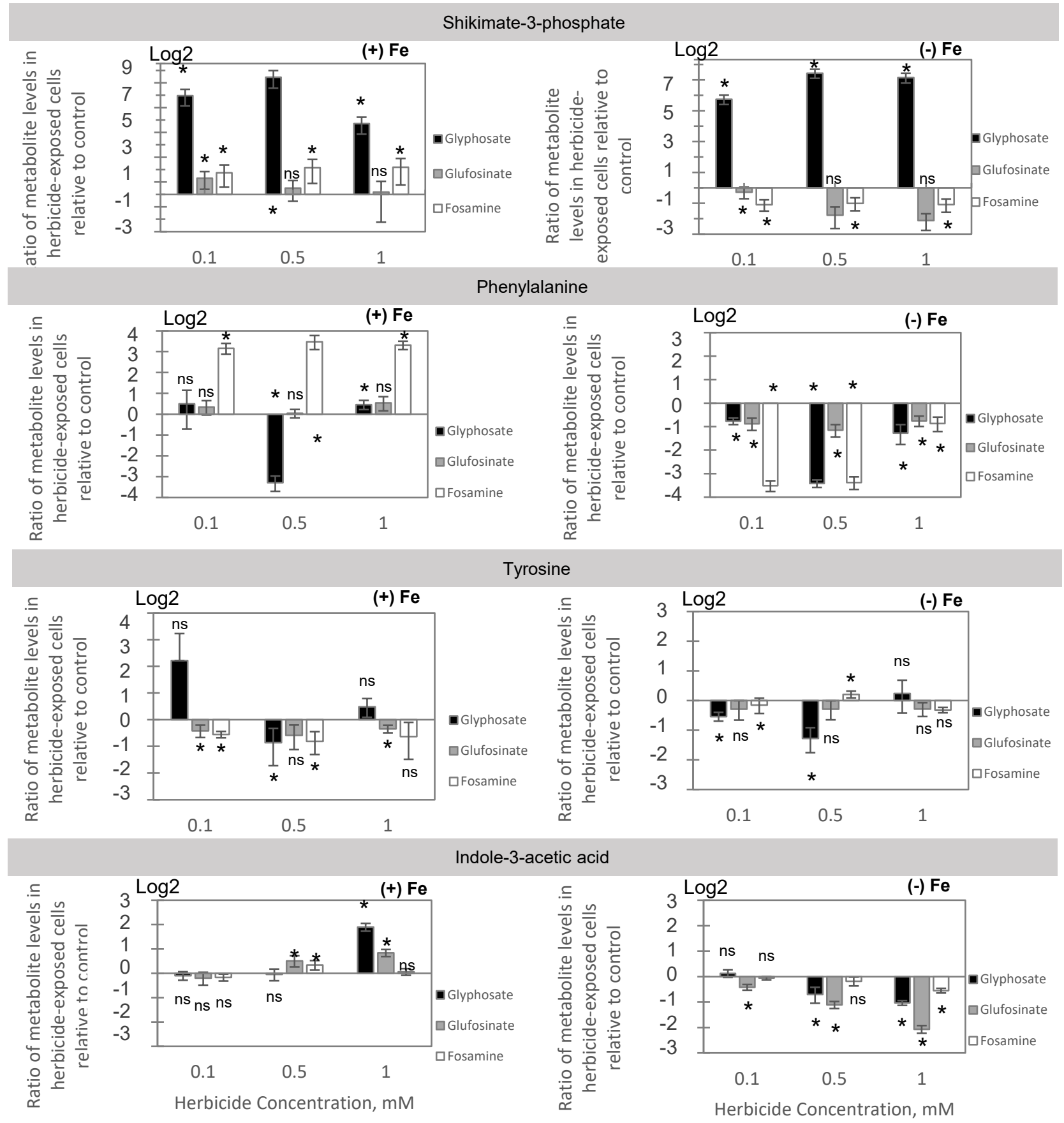

Figure S5. The levels of metabolites involved in the auxin biosynthesis in herbicide-exposed B. megaterium QM B1551 cells relative to control under Fe-replete (left) and Fe-limited (right) conditions. Two-tailed unpaired t-test analysis comparing the ratios obtained with cells grown when each phosphonate herbicide was added to the nutrient medium to cells grown only on the nutrient medium : $p<0.05\left({ }^{*}\right)$, not statistically significant (ns). 


\section{Appendix F. Metabolite levels in herbicide-exposed cells relative to control.}

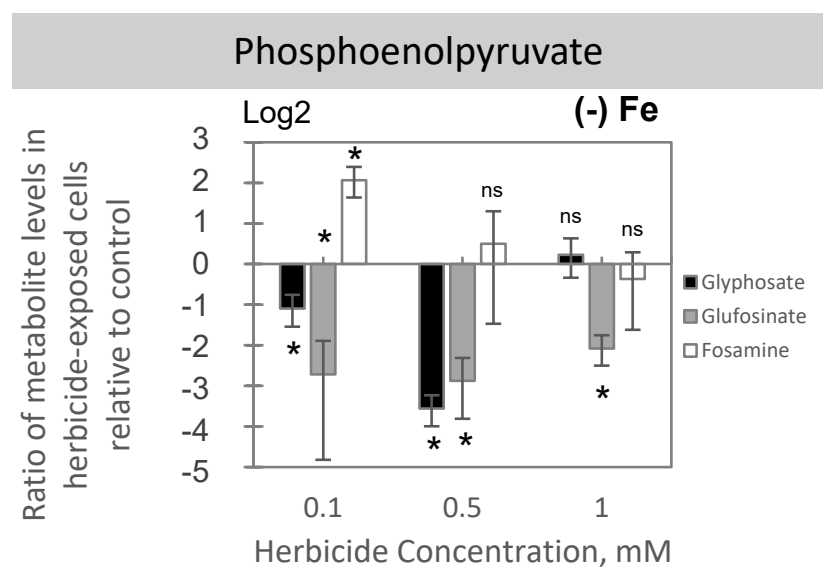

Pyruvate
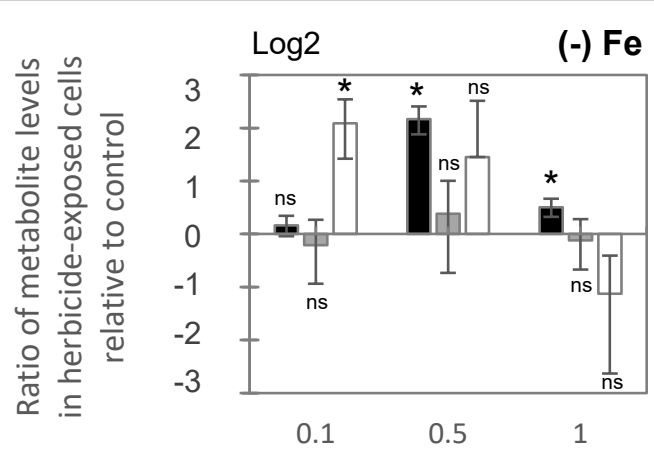

Herbicide Concentration, $\mathrm{mM}$

\section{3-Phosphoglyceric acid}

Log2

$(-) \mathrm{Fe}$
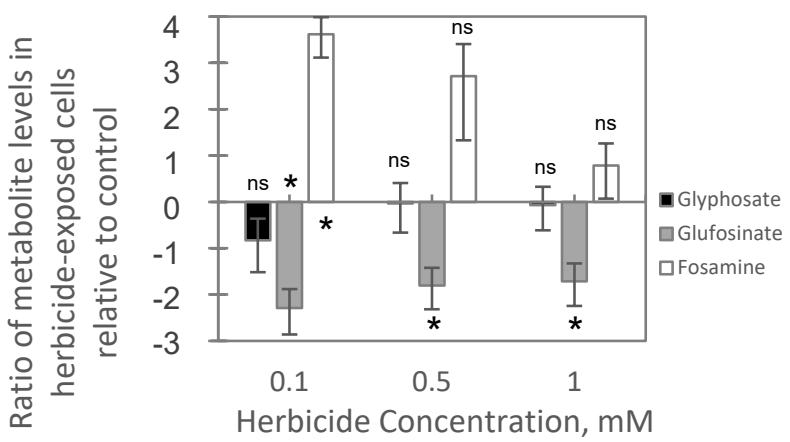

Aspartate
(-) $\mathrm{Fe}$

Log2

$(-) \mathrm{Fe}$
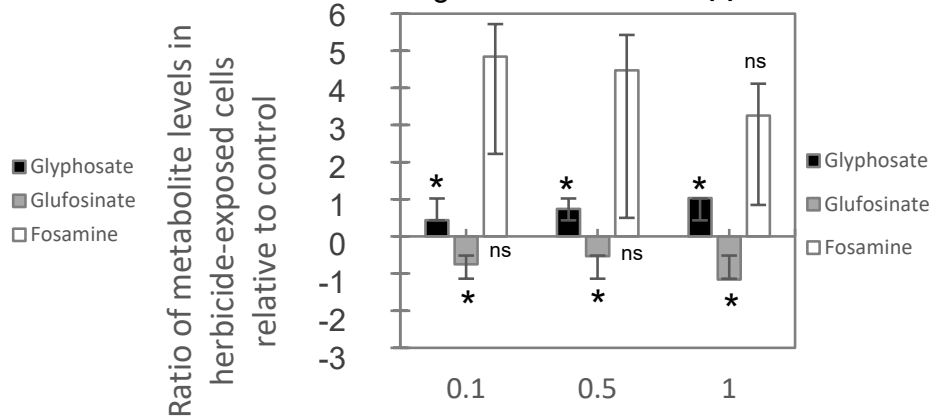

Herbicide Concentration, $\mathrm{mM}$

\section{Pyoverdine}

(-) $\mathrm{Fe}$
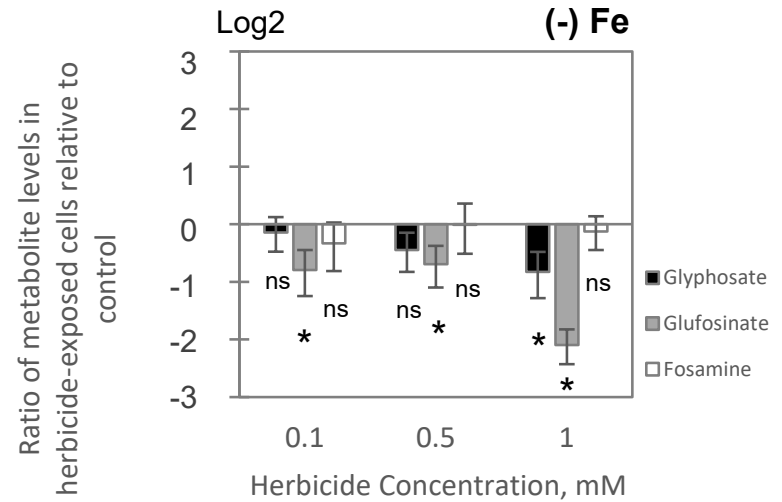

Herbicide Concentration, $\mathrm{mM}$

Figure S6. The levels of metabolites involved in the biosynthesis of the siderophore pyoverdine in herbicide-exposed $P$. protegens $\mathrm{Pf}-5$ cells relative to control under $\mathrm{Fe}-$ replete (left) and Fe-limited (right) conditions. Two-tailed unpaired t-test analysis comparing the ratios obtained with cells grown when each phosphonate herbicide was added to the nutrient medium to cells grown only on the nutrient medium : $p<0.05\left(^{*}\right)$, not statistically significant (ns). 


\section{Appendix G. relative to control.}

Metabolite levels in herbicide-exposed cells

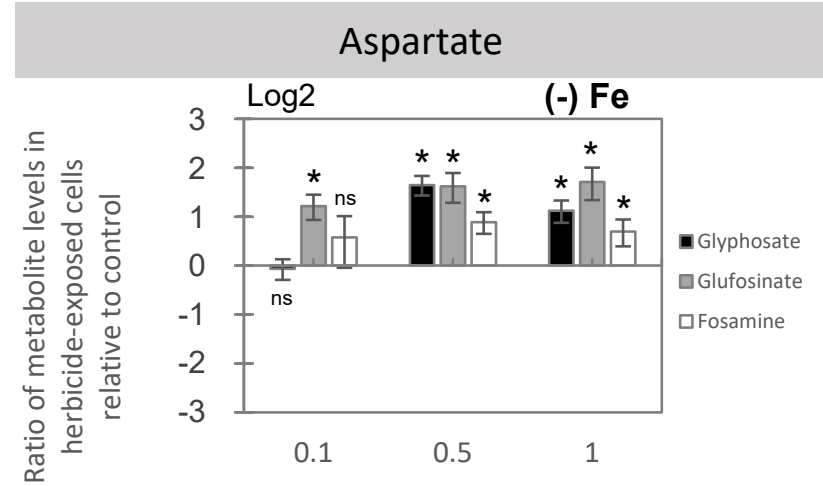

Herbicide Concentration, $\mathrm{mM}$

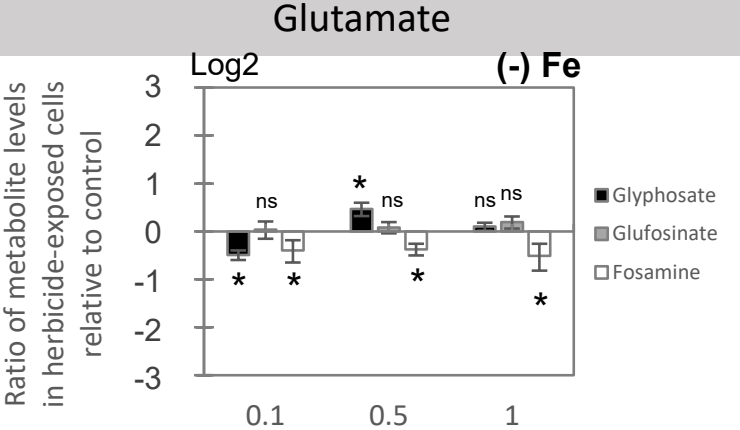

Herbicide Concentration, $\mathrm{mM}$

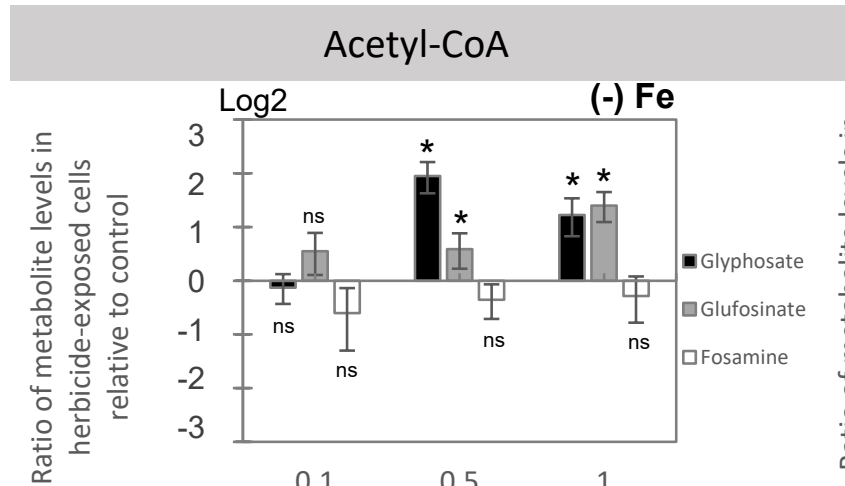

Herbicide Concentration, $\mathrm{mM}$
Citrate

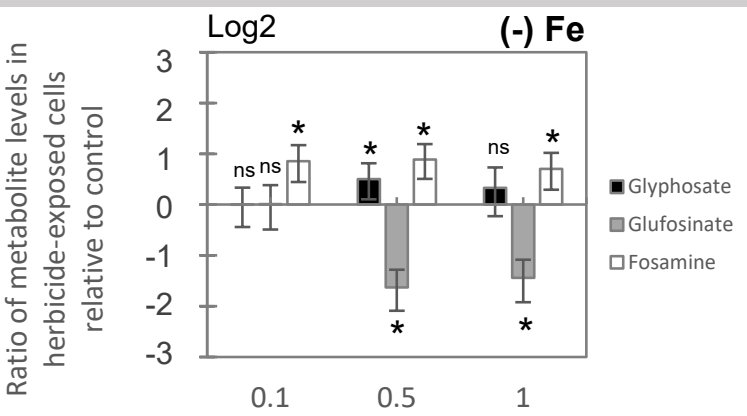

Herbicide Concentration, $\mathrm{mM}$

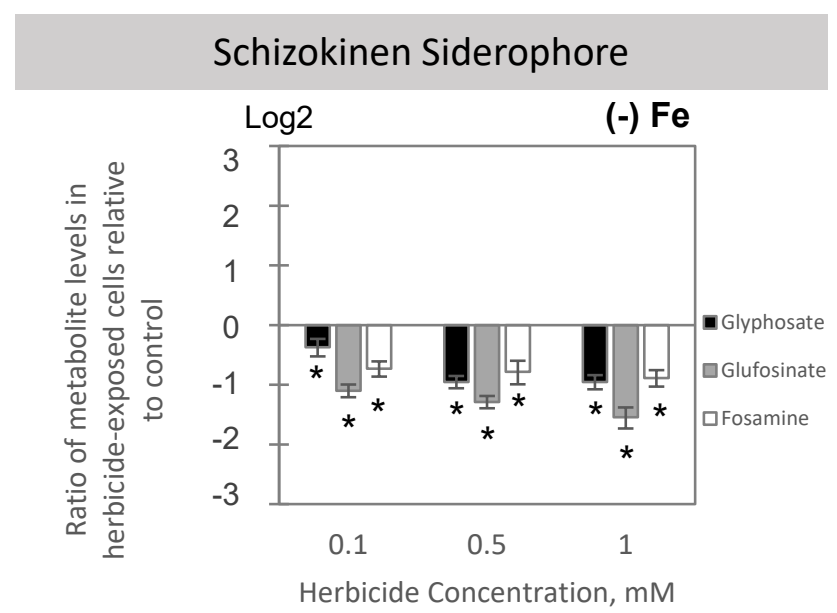

Figure S7. The levels of metabolites involved in the biosynthesis of the siderophore schizokinen in herbicide-exposed P. megaterium QM B1551 cells relative to control under Fereplete (left) and Fe-limited (right) conditions. Two-tailed unpaired t-test analysis comparing the ratios obtained with cells grown when each phosphonate herbicide was added to the nutrient medium to cells grown only on the nutrient medium : $p<0.05\left({ }^{*}\right)$, not statistically significant (ns). 


\section{Metabolite levels in herbicide-exposed cells}

\section{Appendix $\mathrm{H}$. relative to control.}

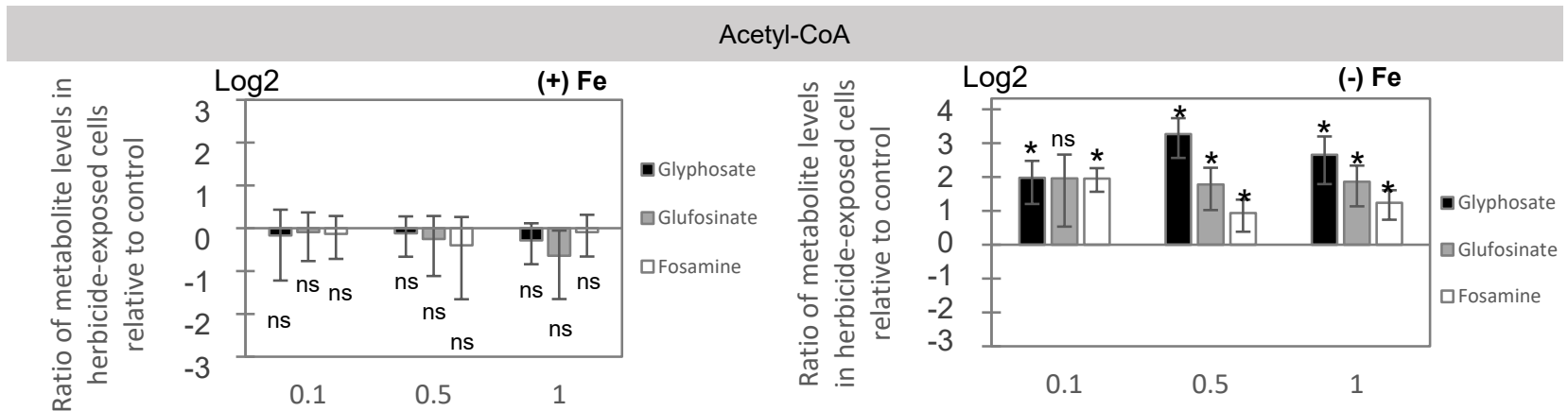

Phloroglucinol

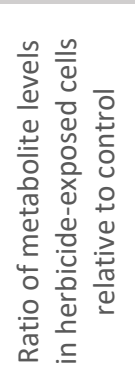

Log2 (+) Fe
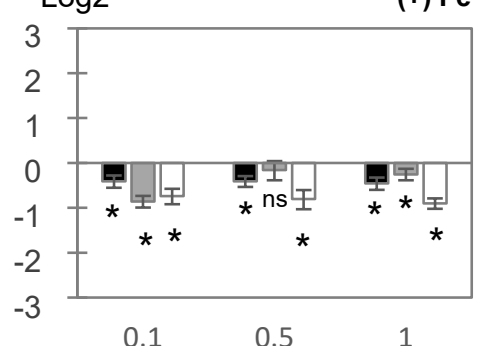

0.1

0.5

1

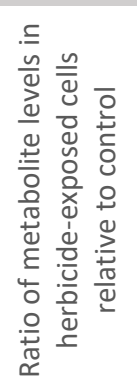

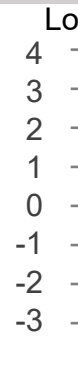

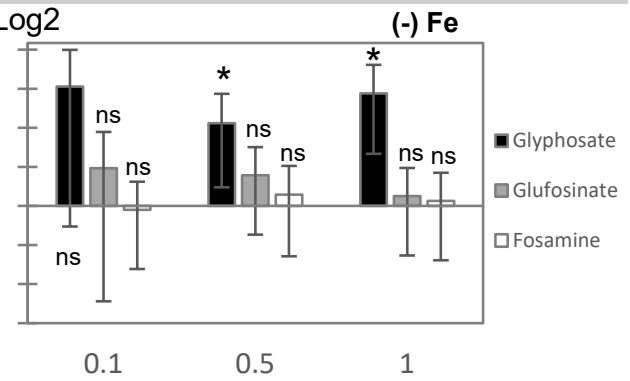

PG-Cl
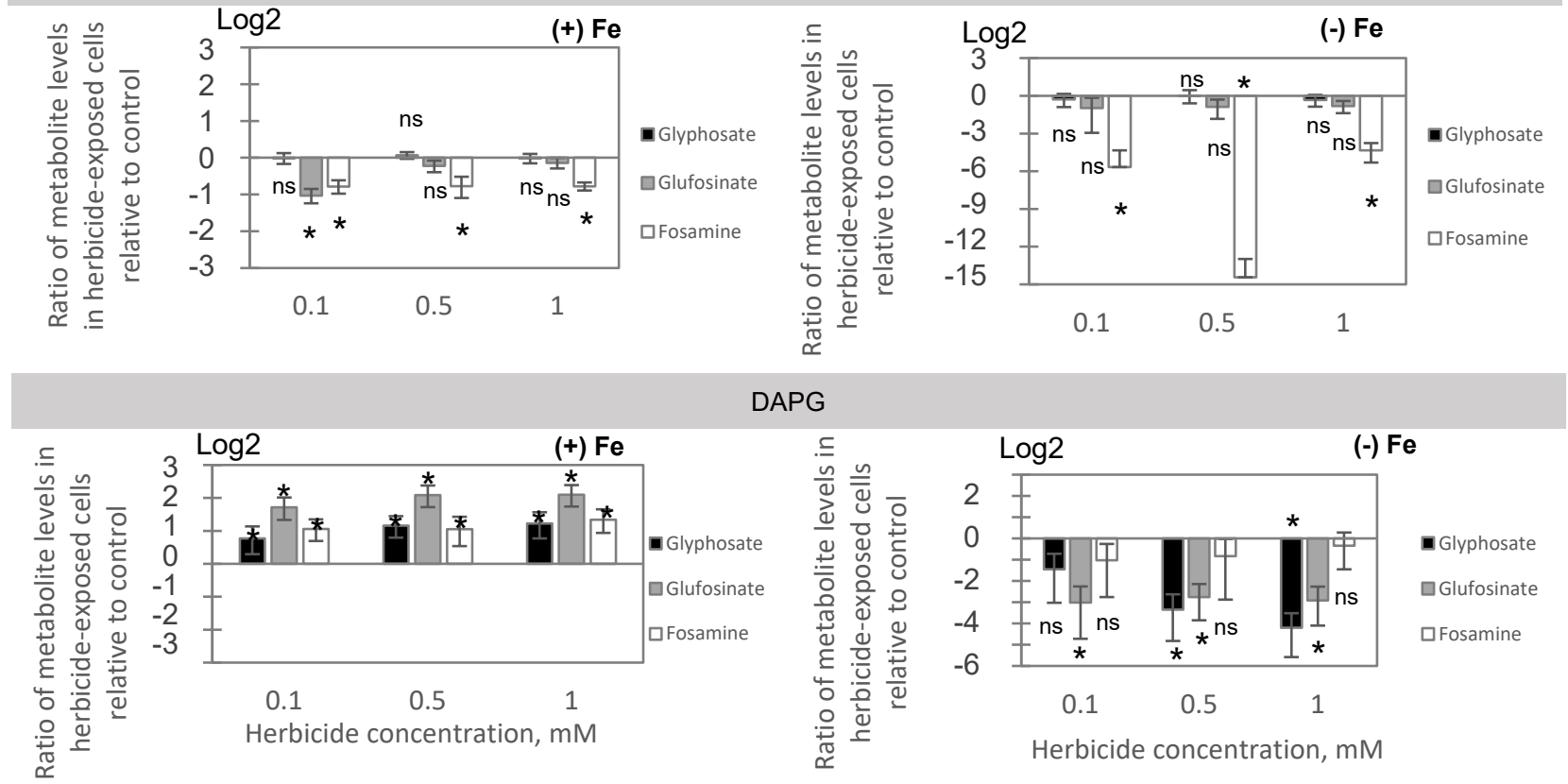

Figure S8. The levels of metabolites involved in the antibiotic DAPG biosynthesis in herbicide-exposed $P$. protegens Pf- 5 cells relative to control under Fe-replete (left) and Fe-limited (right) conditions. Two-tailed unpaired t-test analysis comparing the ratios obtained with cells grown when each phosphonate herbicide was added to the nutrient medium to cells grown only on the nutrient medium : $p<0.05\left(^{*}\right)$, not statistically significant (ns). PG-Cl, 2-chlorobenzene-1,3,5-triol; DAPG, 2,4-diacetylphloroglucinol. 


\section{Appendix I. relative to control.}
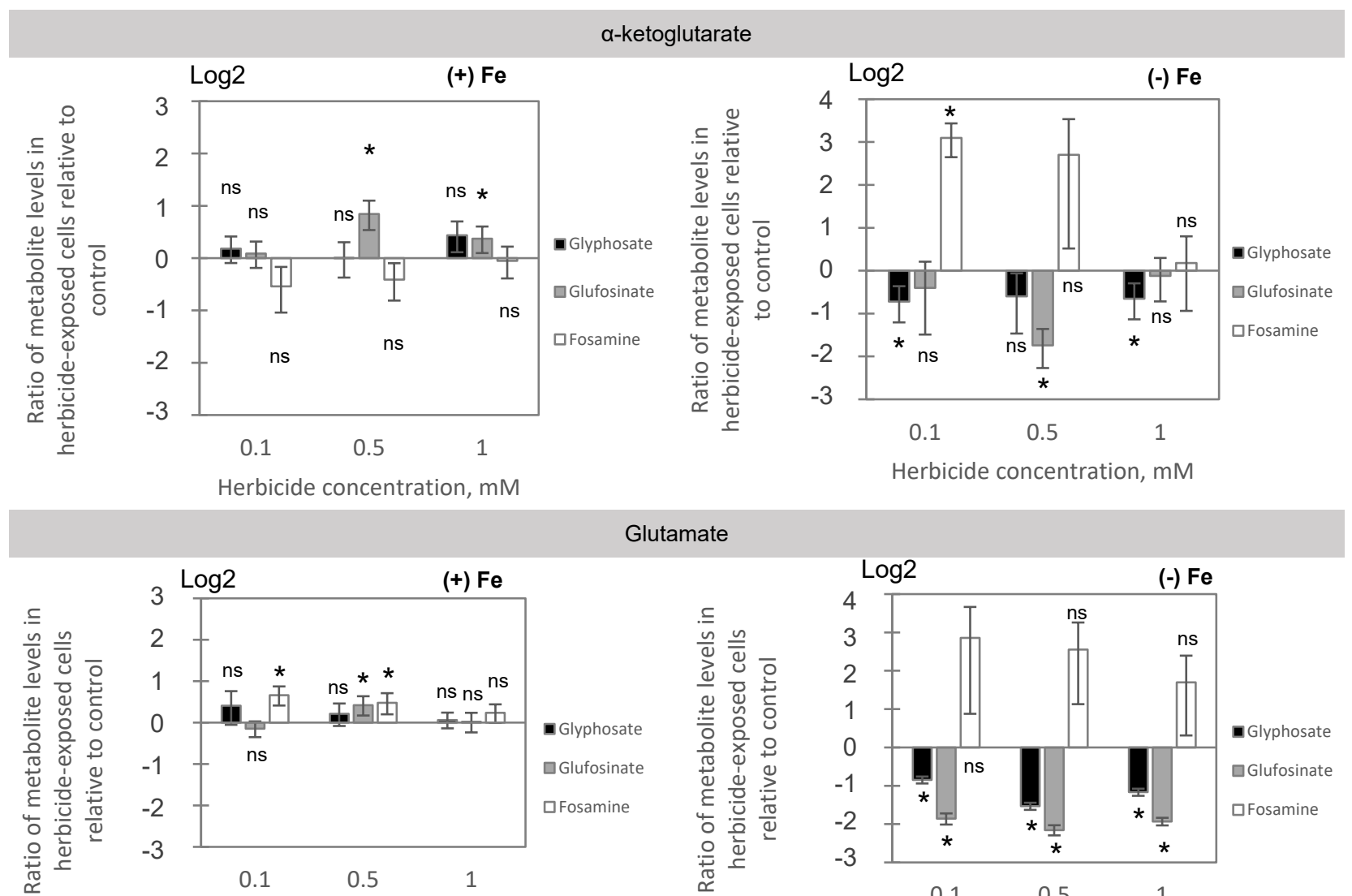

Herbicide concentration, $\mathrm{mM}$
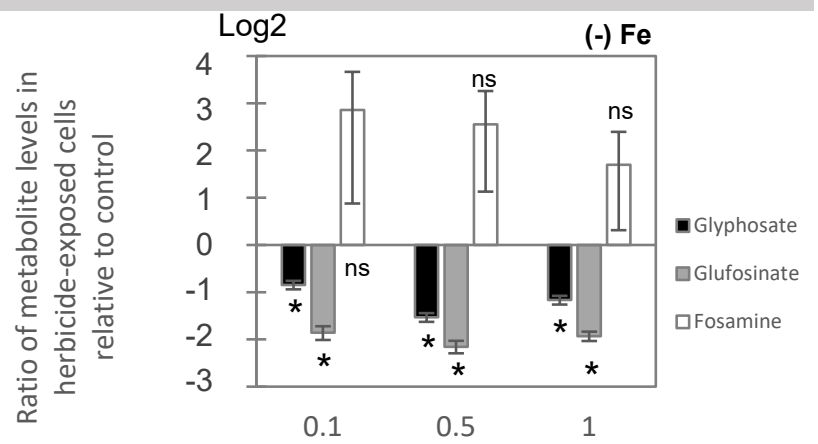

Herbicide concentration, $\mathrm{mM}$

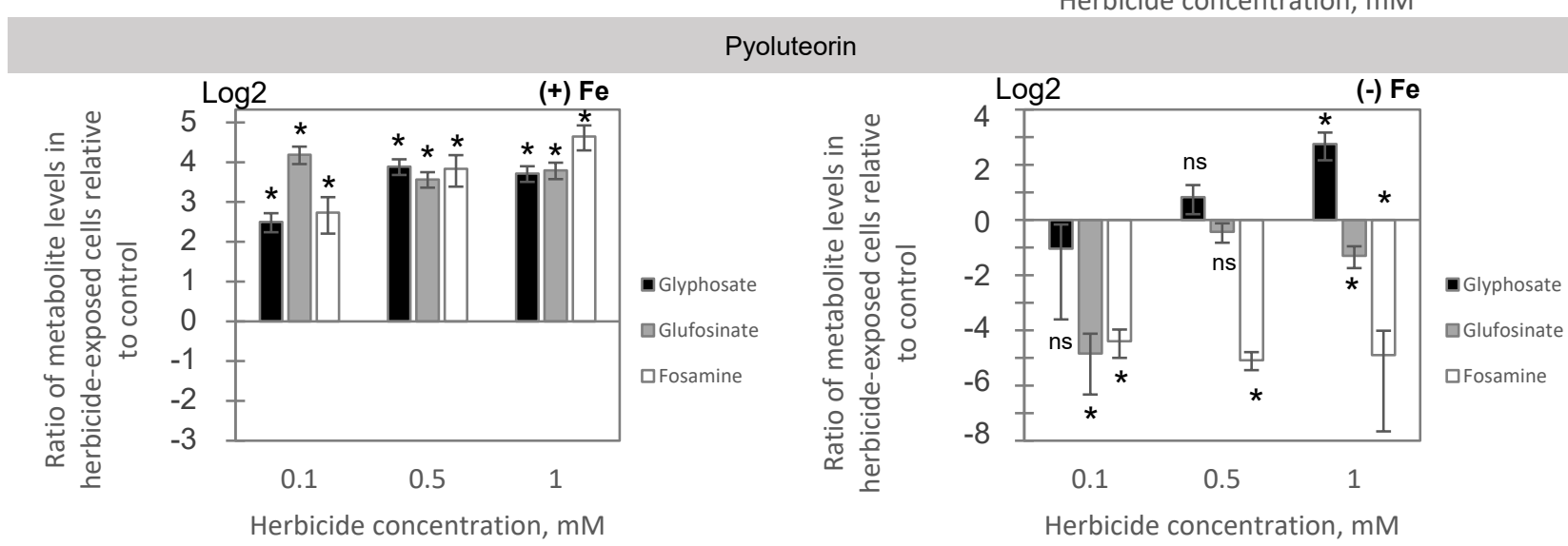

Figure S9. The levels of metabolites involved in the antibiotic pyotuleorin biosynthesis in herbicide-exposed $P$. protegens Pf- 5 cells relative to control under Fe-replete (left) and Fe-limited (right) conditions. Two-tailed unpaired t-test analysis comparing the ratios obtained with cells grown when each phosphonate herbicide was added to the nutrient medium to cells grown only on the nutrient medium : $p<0.05\left(^{*}\right)$, not statistically significant (ns). 


\section{Appendix J.}

\section{The alignment of two EPSP synthases.}

Table S1. The alignment of two EPSP synthases. The results were obtained from blastp (https://blast.ncbi.nlm.nih.gov/Blast.cgi). All data are in the form of percent identity.

\begin{tabular}{|c|c|c|c|c|c|}
\hline Protein & $\begin{array}{l}\text { P05466 } \\
\text { (plant) }\end{array}$ & $\begin{array}{c}\text { Q4K8N1 } \\
\text { (P. protegens) }\end{array}$ & $\begin{array}{c}\text { Q4K7P7 } \\
\text { (P. protegens) }\end{array}$ & $\begin{array}{c}\text { D5DW56 } \\
\text { (B. megaterium) }\end{array}$ & $\begin{array}{c}\text { D5DRE6 } \\
\text { (B. megaterium) }\end{array}$ \\
\hline $\begin{array}{l}\text { P05466 } \\
\text { (plant) }\end{array}$ & ------ & $29.80 \%$ & $24.44 \%$ & $26.36 \%$ & $25.91 \%$ \\
\hline $\begin{array}{c}\text { Q4K8N1 } \\
\text { (P. protegens) }\end{array}$ & $29.80 \%$ & ------ & $29.23 \%$ & $49.76 \%$ & $50.12 \%$ \\
\hline $\begin{array}{c}\text { Q4K7P7 } \\
\text { (P. protegens) }\end{array}$ & $24.44 \%$ & $29.23 \%$ & ------ & $27.51 \%$ & $27.49 \%$ \\
\hline $\begin{array}{c}\text { D5DW56 } \\
\text { (B. megaterium) }\end{array}$ & $26.36 \%$ & $49.76 \%$ & $27.51 \%$ & ------ & $66.51 \%$ \\
\hline $\begin{array}{c}\text { D5DRE6 } \\
\text { (B. megaterium) }\end{array}$ & $25.91 \%$ & $50.12 \%$ & $27.49 \%$ & $66.51 \%$ & ------ \\
\hline
\end{tabular}




\section{Appendix K.}

\section{The alignment of two glutamine synthetases.}

Table S2. The alignment of two glutamine synthetases. The results were obtained from blastp (https://blast.ncbi.nlm.nih.gov/Blast.cgi). All data are in the form of percent identity.

\begin{tabular}{|c|c|c|c|c|c|c|}
\hline Protein & $\begin{array}{c}\text { Q4KJQ3 } \\
\text { (P. protegens) }\end{array}$ & $\begin{array}{c}\text { D5DQ10 } \\
\text { (B. megaterium) }\end{array}$ & $\begin{array}{c}\text { Q45NB6 } \\
\text { (plant) }\end{array}$ & $\begin{array}{c}\text { Q45NB7 } \\
\text { (plant) }\end{array}$ & $\begin{array}{c}\text { Q45NB2 } \\
\text { (plant) }\end{array}$ & $\begin{array}{c}\text { Q6RUJ0 } \\
\text { (plant) }\end{array}$ \\
\hline $\begin{array}{c}\text { Q4KJQ3 } \\
\text { (P. protegens) }\end{array}$ & ----- & $41.72 \%$ & $23.21 \%$ & $22.92 \%$ & $22.43 \%$ & $23.25 \%$ \\
\hline $\begin{array}{c}\text { D5DQ10 } \\
\text { (B. megaterium) }\end{array}$ & $41.72 \%$ & ---- & $26.72 \%$ & $26.72 \%$ & $25.57 \%$ & $27.14 \%$ \\
\hline $\begin{array}{c}\text { Q45NB6 } \\
\text { (plant) }\end{array}$ & $23.21 \%$ & $26.72 \%$ & ----- & $99.92 \%$ & $76.20 \%$ & $82.65 \%$ \\
\hline $\begin{array}{c}\text { Q45NB7 } \\
\text { (plant) }\end{array}$ & $22.92 \%$ & $26.72 \%$ & $99.92 \%$ & ----- & $76.49 \%$ & $82.94 \%$ \\
\hline $\begin{array}{c}\text { Q45NB2 } \\
\text { (plant) }\end{array}$ & $22.43 \%$ & $25.57 \%$ & $76.20 \%$ & $76.49 \%$ & ----- & $82.65 \%$ \\
\hline $\begin{array}{c}\text { Q6RUJ0 } \\
\text { (plant) }\end{array}$ & $23.25 \%$ & $27.14 \%$ & $82.65 \%$ & $82.94 \%$ & $82.65 \%$ & ---- \\
\hline
\end{tabular}




\section{Appendix L.}

High resolution LC-MS run charts for all compounds measured.

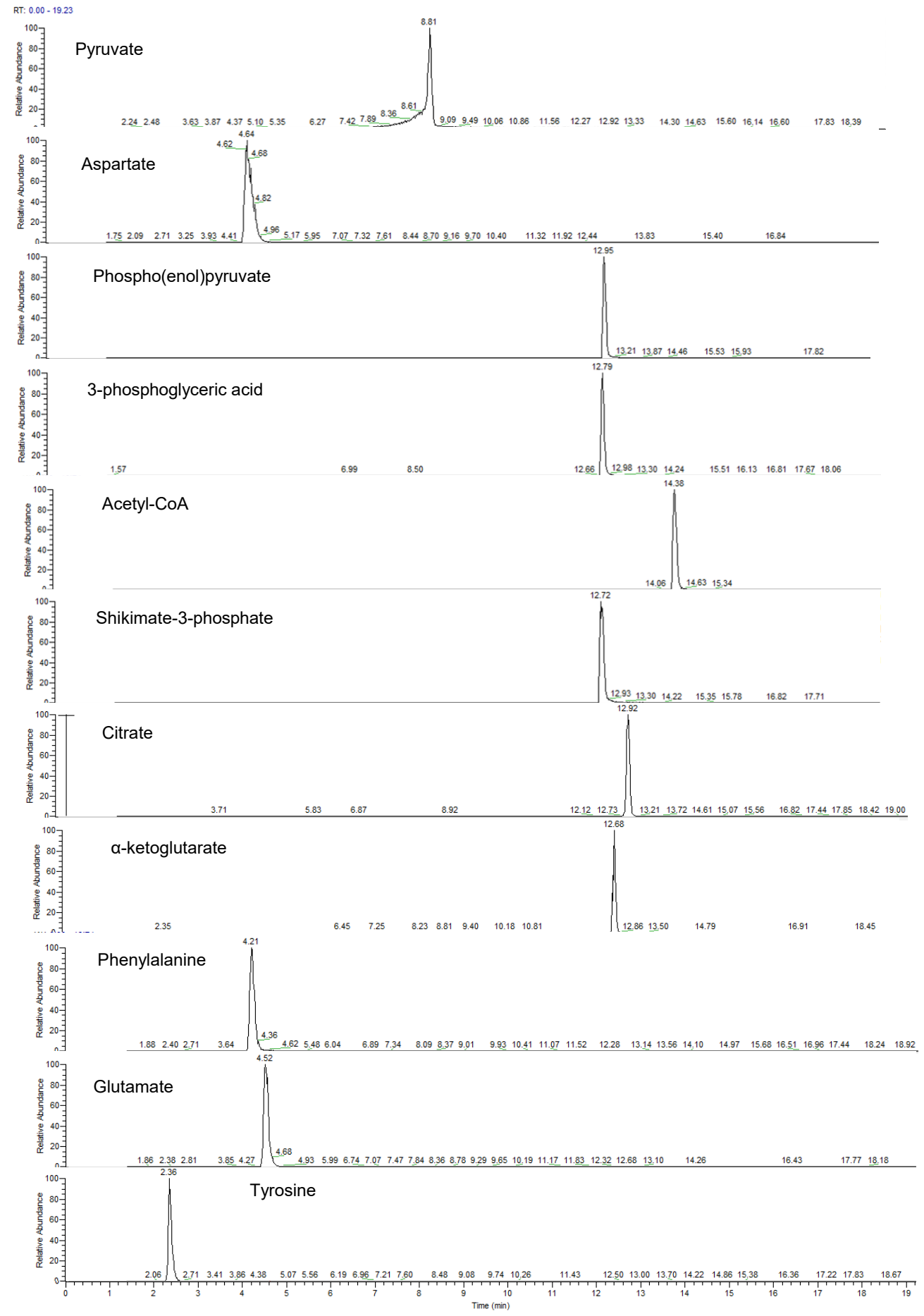

Figure S10. The high resolution LC-MS run chart of each compound investigated in the metabolite analysis. 

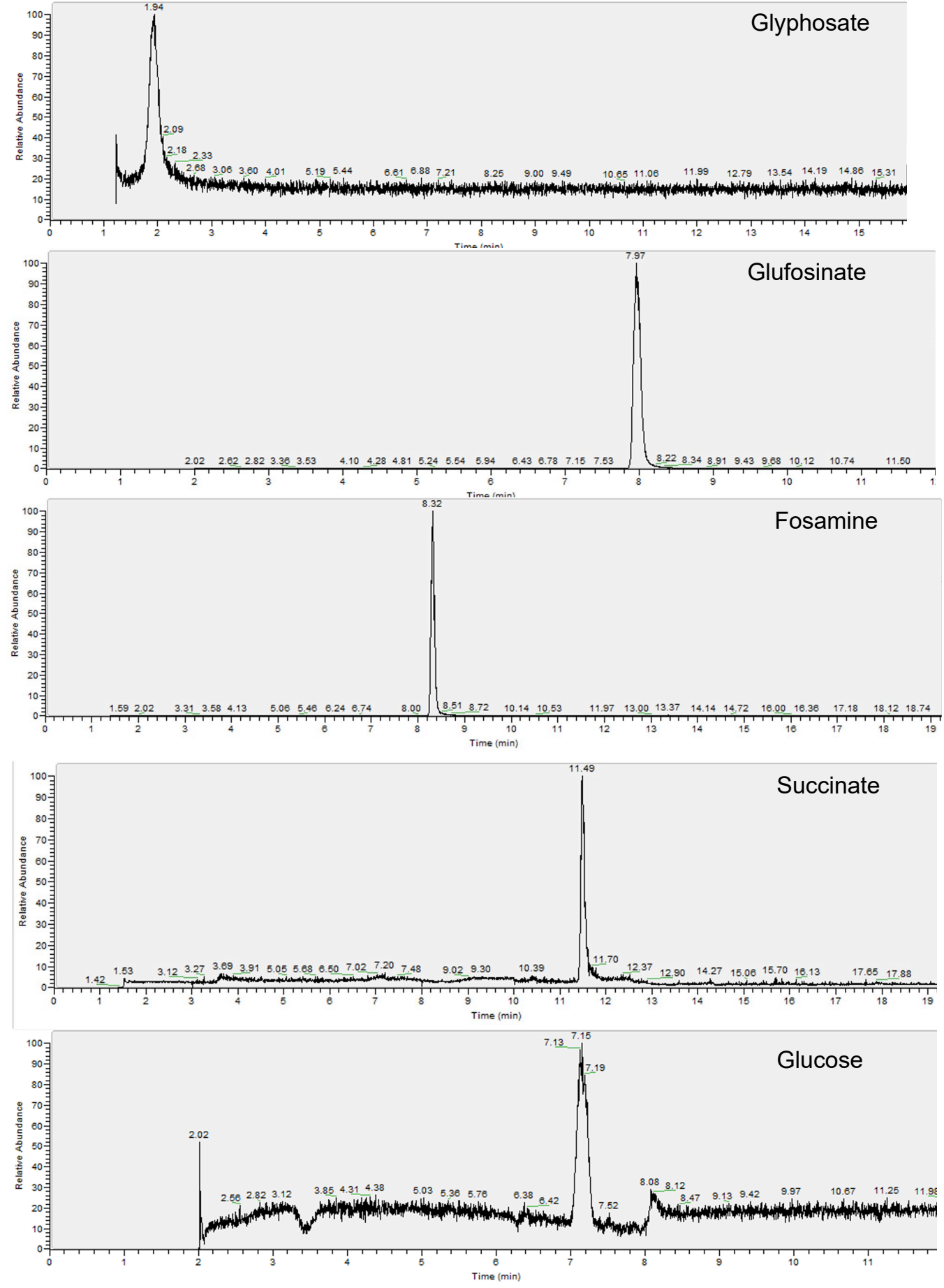

Figure S11. The high resolution LC-MS run chart of each phosphonate herbicide and carbon substrate investigated. 


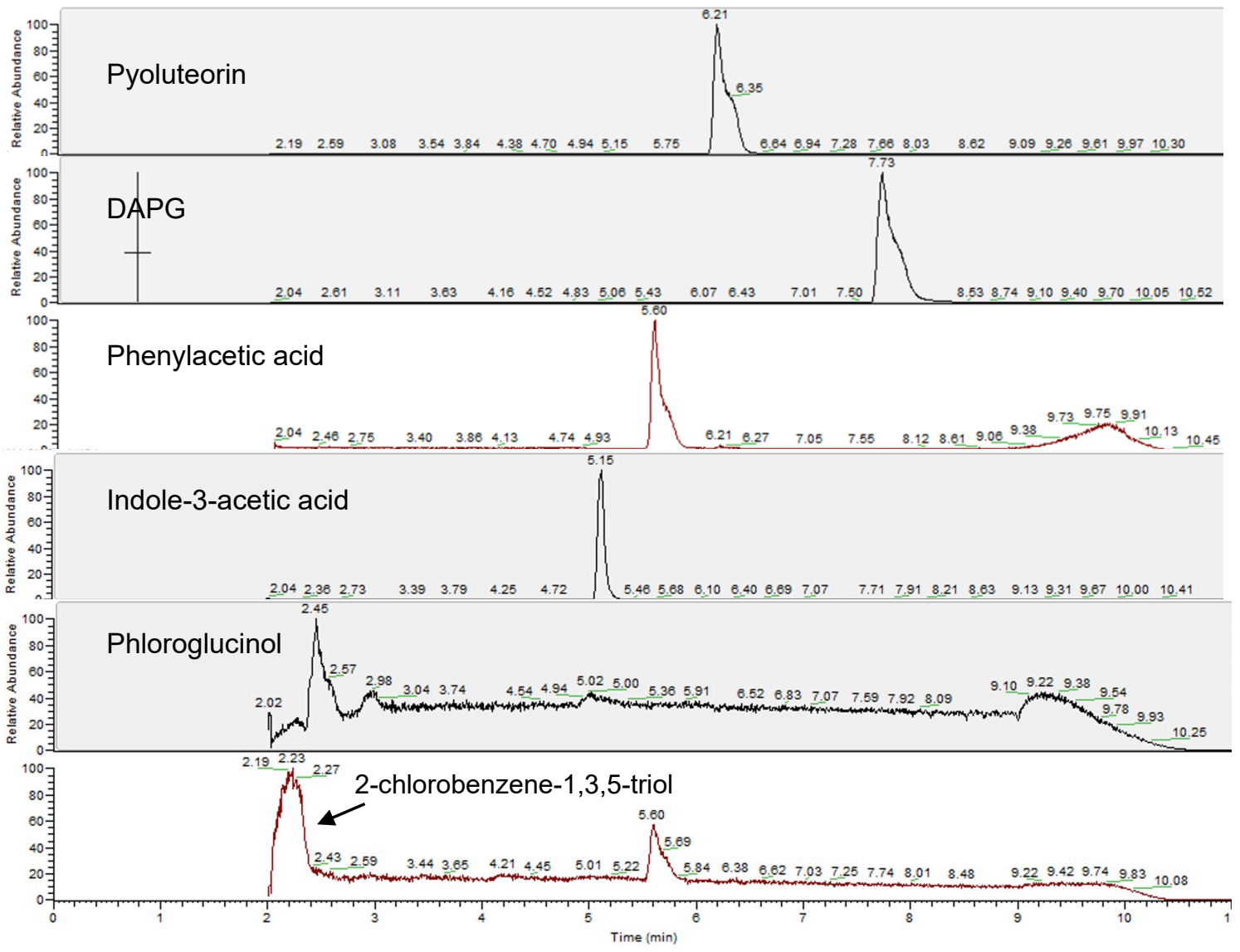

Figure S12. The high resolution LC-MS run chart of each plant beneficial compounds investigated. 